www.jmscr.igmpublication.org Impact Factor 5.244

Index Copernicus Value: 5.88 ISSN (e)-2347-176x ISSN (p) 2455-0450 crossref DOI: http://dx.doi.org/10.18535/jmscr/v4i6.69

Journal Of Medical Science And Clinical Research

\title{
Role of Aging, Hypertension and Dyslipidaemia in Carotid Intimal Medial Thickness among Patients with Ischemic Stroke Proven By Computed Tomography
}

\author{
Authors \\ Dr Sangram S Mangudkar ${ }^{1}$, Dr Kiran Shinde ${ }^{2}$, Dr Gajanan D Khadkikar ${ }^{3}$, \\ Dr Jyoti A Landge 4 \\ ${ }^{1}$ Associate Professor, Dept of Medicine, Dr D Y Patil Medical College, Pimpri, Pune \\ ${ }^{2}$ Senior resident, Dept of Medicine Dr D Y Patil Medical College, Pimpri, Pune \\ ${ }^{3}$ Senior resident, Dept of Medicine Dr D Y Patil Medical College, Pimpri, Pune \\ ${ }^{4}$ Assistant Professor, Dept of Community Medicine, Dr D Y Patil Medical College, Pimpri, Pune \\ Corresponding Author \\ Dr Jyoti A Landge \\ Dept of Community Medicine, Dr D Y Patil Medical College, Pimpri, Pune 411018 \\ Email: jlandge11@gmail.com
}

\begin{abstract}
:
Background: Cerebrovascular accident or stroke is defined by an abrupt onset of neurological deficit that is attributable to a focal vascular cause. This may result from brain infarction or hemorrhage. Carotid intimalmedial thickness (IMT) predicts future vascular events in the general population. Most scientists studying the relation of intimal medial thickness with atherosclerosis have concentrated their efforts on coronary artery disease with less data available on the relation between intimal medial thickness and stroke, Present study was carried out to study the association of an increase in carotid artery intimal-medial thickness with aging, hypertension and dyslipidaemia in patients with ischemic stroke proven by computed tomography.

Material and methods: A cross sectional study of 106 pateints fulfilled with inclusion criteria was carried out in dept of general medicine at Dr D Y Patil Medical College, pimpri, Pune. Informed consent was taken from patients, they underwent history taking, proper clinical examination, radiological and biochemical investigations Collected data entered in excel and results were analyzed using Chi-square test \& Independent Sample "T test" in SPSS 20.

Result: out of 106, the largest group was in the age range of $60-70$ years, mean age of 61 years with range of 23- 83 years. There were 69 males (65\%) and 37 females (35\%) in the study. Hypertension (60\%) was the most common risk factor, other common risk factors being smoking (24\%), and ischemic heart disease (20\%).

Conclusion: The study showed old age, hypertension, dyslipidaemia is associated with ischemic stroke by increasing carotid intimal-medial thickness (IMT).

Keywords: Dyslipidemia, Hypertension, Ischemic stroke, Intimal-medial thickness
\end{abstract}




\section{Introduction}

Stroke is a major cause of morbidity and mortality worldwide. This may result from brain infarction or hemorrhage ${ }^{[1]}$. Carotid atherosclerosis is a reasonable risk factor for cerebral ischemic stroke. Atherosclerosis afflicts multiple vascular beds, accounting for nearly all of coronary heart disease and some proportion of ischemic strokes ${ }^{[2]}$. There is a growing belief that carotid intimal medial thickness can be regarded as an indicator of generalized atherosclerosis ${ }^{[3]}$.

Most scientists studying the relation of intimal medial thickness with atherosclerosis have concentrated their efforts on coronary artery disease with less data available on the relation between intimal medial thickness and stroke. Four major randomized controlled trials have studied the relation of intimal medial thickness and stroke or coronary artery disease ${ }^{[4-7]}$.

At three years of follow up, the stroke risk increased gradually with increasing IMT. The odds ratio for stroke per standard deviation increase in IMT $(0.163 \mathrm{~mm})$ was 1.41 . When subjects with a previous myocardial infarction or stroke were excluded, the odds ratio was 1.57 for stroke. Thus, increased common carotid IMT is associated with future cerebrovascular and cardiovascular events ${ }^{[5]}$.Increased intima-media thickness, an indicator of subclinical disease, may reflect the consequences of past exposures to risk factors. The addition of measurements of intimamedia thickness to risk equations may help to identify asymptomatic persons who would benefit from aggressive preventive measures ${ }^{[8] \text {. }}$

Present study was carried out to study the association of an increase in carotid artery intimalmedial thickness with some risk factors of stroke in patients with ischemic stroke proven by computed tomography.

\section{Objectives}

1. To study the carotid intimal thickness in patients with Ischemic stroke proven by computed tomography or MRI.
2. To study the lipid profile in patients with ischemic stroke proven by computed tomography or MRI.

3. To study the correlation between the increase in carotid artery intimal medial thickness with aging, hypertension and dyslipidaemia in patients with ischemic stroke proven by computed tomography or MRI.

\section{Materials and Methods}

cross sectional study was conducted at Dr D Y Patil medical college, pimpri, pune for a period of 18 months (July 2012-dec-2013).We screened all patients of stroke presenting to medicine ward of Dr D Y Patil medical college, within 30 days of onset of symptoms for period of 18 months. Patients fulfilling inclusion criteria were enrolled in the study.

\section{Inclusion Criteria:}

1. Onset of symptoms within 30 days of presentation to the hospital

2. CT proven infarct

3. Patients amenable to being transported to Radiology department for carotid Doppler study

\section{Exclusion Criteria:}

1. Patients in whom CT scan is not feasible

2. Patients in whom CT scan showed hemorrhage

3. Patients in whom CT scan was normal

4. Patient too ill to be transported to the Radiology department for carotid Doppler study

We screened 207 patients out of which 101 patients were excluded. CT scan showed haemorrhage in 41 patients, CT scan was not feasible in 37 patients, CT scan was normal in 13 patients and 10 were Patient too ill to be transported to the Radiology department for carotid Doppler study and were excluded from study. A total of 106 patients were studied.

Information like age, sex, symptoms, time interval to reach hospital, associated co-morbid conditions such as hypertension, diabetes, tobacco use, 
alcohol consumption, family and past history, complete clinical examination and treatment details were collected.

\section{Investigations}

All patients who fulfilled inclusion criteria underwent CT scan and type of stroke classified on the basis of TOAST criteria. Blood was withdrawn from all patients for creatinine, hemoglobin, mean corpuscular volume, fasting lipid profile, fasting blood sugar. All patients underwent ECG to look for evidence of ischemic heart disease. All patients fit to be transported were shifted to the Radiology department and underwent carotid Doppler imaging using B-mode ultrasound.

\section{CT scan}

Infarcts were classified into lacunar infarcts and cortical infarcts.

\section{Intimal Medial Thickness Measurement:}

All patients were examined in supine position with neck extended with a pillow under the shoulder. Ultrasonography of the common carotid artery, carotid bifurcation, and internal carotid artery of the left and right carotid arteries was performed with a $7.5-\mathrm{MHz}$ linear-array transducer.

On a longitudinal, two-dimensional ultrasound image of the carotid artery, the anterior (near) and posterior (far) walls of the carotid artery are displayed as two bright white lines separated by a hypoechogenic space. The distance between the leading edge of the first bright line of the far wall (lumen-intima interface) and the leading edge of the second bright line (media-adventitia interface) indicates the intima-media thickness. For the near wall, the distance between the trailing edge of the first bright line and the trailing edge of the second bright line at the near wall provides the best estimate of the near-wall intima-media thickness Left carotid was examined first and then the right. Three sites were selected in each carotid artery. The carotid artery bulb was traced and the first reading is taken $1 \mathrm{~cm}$ proximal to the carotid bulb. The second reading is taken within the bulb and the site with maximum diameter recorded. The third reading is taken $1 \mathrm{~cm}$ distal to the carotid bulb along the internal carotid artery. For all three sites both near wall and far wall measurements are taken. The recordings are taken upto 2 decimal points. An average of each artery is computed taking into account all six readings.

At the time, a note was made of presence of any plaque or calcification and duly recorded.

IMT measured on the frozen frame of a suitable longitudinal image with the image magnified to achieve a higher resolution of detail. The IMT measurement obtained from the 3 sites are averaged and the average of 6 measurements used. The CIMT readings were recorded as

$\mathrm{A}=$ far wall of common carotid; $\mathrm{B}=$ near wall of common carotid; $\mathrm{C}=$ far wall of carotid bulb

$\mathrm{D}=$ near wall of carotid bulb; $\mathrm{E}=$ far wall of internal carotid; $\mathrm{F}=$ near wall of internal carotid

Thus, the mean CIMT $=\mathrm{A}+\mathrm{B}+\mathrm{C}+\mathrm{D}+\mathrm{E}+\mathrm{F} / 6$

The carotid intimal-medial thickness expected for age of patient was calculated using the formula:

IMT $=(0.009 *$ Age $)+0.116[9]$

\section{Lipid profile}

The levels of the individual fractions of the lipid profile were interpreted as follows, in accordance with the NCEP (National Cholesterol Education Program) guidelines ${ }^{[10]}$.

Total cholesterol - Desirable $<200 \mathrm{mg} / \mathrm{dl}$, borderline- 200-239 mg/dl, and High- >240 mg/dl LDL cholesterol - Desirable $<130 \mathrm{mg} / \mathrm{dl}$, borderline- $130-159 \mathrm{mg} / \mathrm{dl}$, and High- $>160 \mathrm{mg} / \mathrm{dl}$ HDL cholesterol - Desirable $>60 \mathrm{mg} / \mathrm{dl}$, borderline- 40-60 mg/dl, and low- $<40 \mathrm{mg} / \mathrm{dl}$

Triglycerides- Desirable $<250 \mathrm{mg} / \mathrm{dl}$, borderline250-350mg/dl, and High- >350mg/dl

\section{Hypertension}

Hypertension was defined according to the $7^{\text {th }}$ JNC guidelines ${ }^{[11] .}$

Normal- 120/80mmHg, Pre-Hypertension-120139/80-89 mmHg, 
Stage -I-hypertension- 140-159/90-99mmHg, Stage - II-hypertension- $>=160 />=100 \mathrm{mmHg}$

Or patient on anti-hypertensive medication

\section{Diabetes mellitus}

Diabetes mellitus is defined as fasting blood glucose $>126 \mathrm{mg} / \mathrm{dl}^{[12]}$ or patient on any OHA or Insulin therapy.

The fasting blood sample was analyzed on ERBA Smart Lab autoanalyzer using the ERBA REKT201 kit.

\section{Statistical Analysis}

Collected data entered in excel and results were statistically analyzed using Chi-square test \& Independent Sample "T test" in SPSS 20.

\section{Results}

Of the total 106 patients, the largest group was in the age range of $60-70$ years. The mean age was 61 years with minimum of 23 years and maximum of 83 years. There were 69 males $(65 \%)$ and 37 females $(35 \%)$ in the study. The majority of patients $(90 \%)$ were educated less than Class X, only $10 \%$ having studied beyond Class X. The largest group comprises unskilled workers (51\%). Most of the cases were sleeping when they had stroke $(52 \%)$ with most others going about their routine activities (36\%). Most patients presented to the hospital within the first $24 \mathrm{hrs}(87 \%)$ with $20 \%$ in the first $6 \mathrm{hrs}$ of onset of neurological deficit. Hypertension was the most common risk factor present in $60 \%$ of patients, other common risk factors being smoking in $24 \%$, ischemic heart disease in $20 \%$. No overt modifiable risk factors were present in $20 \%$ of study patients. [Table 1] The mean intimal medial thickness of patients was 0.83 with minimum of 0.45 and maximum of 1.096. Of 106 patients, 84 patients had an IMT > or $=$ to $0.7(79 \%)$ and 22 patients had an IMT < $0.7(21 \%)$.

\section{Discussion}

Early detection of atherosclerosis is desirable to prevent the occurrence of atherosclerotic events like stroke and myocardial infarction. The carotid intima media thickness is a non invasive technique used in the diagnosis of atherosclerotic disease which is $70.7 \%$ sensitive and $59.0 \%$ specific in predicting CAD. Similarly, the risk of stroke increases with increasing intimal-medial thickness [5].

Our study was carried out in 106 patients fulfilling inclusion criteria for period of 18 months. The mean age of our study population was 61 years with minimum of 23 years and maximum of 83 years, 69 patients older than 60 years of age. Earlier studies of Bhattcharya $\mathrm{S}$ et al, Dalal $\mathrm{P}$ et al, Sridharan $\mathrm{S}$ et al showed that the mean age of onset of stroke for men in India ranges from 63-65 for men and 57-68 for women ${ }^{[13-15]}$. These age group findings are similar to our study.

Males comprised $65 \%$ and females $35 \%$ of the study population.

In our study, the single most common risk factor was hypertension with $88 \%$ of patients having a blood pressure recording of $>=140 / 90 \mathrm{~mm} \mathrm{Hg}$. There was significant association between hypertension and IMT (Fig 1). Uncontrolled hypertension was found to be the single most important risk factor for the development of strokes in the MONICA report published in 1997 [16], Another study by Debalina Sengupta et al showed Most of the patient were hypertensive with Mean SBP is $154.60 \mathrm{~mm}$ of $\mathrm{Hg}$ \& DBP is $97.72 \mathrm{~mm}$ of $\mathrm{Hg}$. ${ }^{[17]}$

The uniform standard cut off value of carotid IMT has not been defined with values in different studies. Sun, Y et al ${ }^{[18]}$ have taken the cut off value as $0.68 \mathrm{~mm}$. Taking this cut off value, asymptomatic individuals with carotid IMT $>0.68 \mathrm{~mm}$ had increased risk of carotid atherosclerosis. Geroulakos, $\mathrm{G}$ et al ${ }^{[19]}$ took IMT $>$ or $=0.85 \mathrm{~mm}$ as a criterion for the prediction of coronary artery disease. Lemne, $\mathrm{C}$ et al ${ }^{[20]}$ have found $0.72 \mathrm{~mm}$ of carotid IMT to be significant in their studies of carotid intima-media thickness and plaque in borderline hypertension. Lacroix, $\mathrm{P}$ et al ${ }^{[21]}$ have demonstrated that carotid IMT $>0.7 \mathrm{~mm}$ was a predictor of secondary events after coronary 
angioplasty $(\mathrm{p}=0.03)$ in univariate analysis. Thus considering the data from the above mentioned studies, a cut-off of $0.7 \mathrm{~mm}$ for CIMT was selected as being significant in our study.

The mean intimal medial thickness of the common carotid-internal carotid artery measured by carotid artery Doppler in our patients of ischemic stroke was $0.83 \mathrm{~mm}$ with a minimum of $0.45 \mathrm{~mm}$ and maximum of $1.096 \mathrm{~cm}$. The mean expected intimal-medial thickness was $0.67 \mathrm{~mm}$ calculated according to the age of study patients [Table 2]. The difference between the measured and the expected IMT of the study patients for their age was significant at 5\% level of significance with $p$ $<0.001$.Thus, we surmise that in patients of ischemic stroke, there is an increase in the intimalmedial thickness of the common carotid-internal carotid artery.

There was linear correlation of intimal medial thickness with age, intimal medial thickness increasing as age increased $(\mathrm{p}<0.001)$. Only 6 patients in the study were less than 40 years of age all of whom had an IMT less than $0.54 \mathrm{~mm}$. Of the 69 patients older than 60 years of age, 50 [73\%] had an IMT more than $0.75 \mathrm{~mm}$. There is a linear correlation between age and IMT which is statistically significant [ $p<0.001]$ [Fig 2].

The cut off value for normal total cholesterol is taken as $<200 \mathrm{mg} / \mathrm{dl}$, with borderline between 200-239 and increased total cholesterol > 240 $\mathrm{mg} / \mathrm{dL}$. Of the 84 patients [80\%] who had an abnormal intimal-medial thickness, 48 patients [57\%] had an abnormal total cholesterol level and 36 patients [43\%] had normal total cholesterol. Of the 22 patients [20\%] with normal IMT, 14 patients [64\%] had a normal total cholesterol level and 8 patients [36\%] had abnormal total cholesterol [Table 3]. The relation of total cholesterol and intimal-medial thickness was not statistically significant.

The cut-off value for normal LDL was $<130$ $\mathrm{mg} / \mathrm{dL}$, borderline high LDL as 130-159 and increased LDL as > 160 and IMT considered significant at $0.7 \mathrm{~mm}$. Of the 84 patients with abnormal IMT, 48 patients [57\%] had abnormal
LDL and 36 patients [43\%] had normal LDL. Of the 22 patients [20\%] with normal IMT, 14 patients [64\%] had normal LDL and 8 patients [36\%] had abnormal LDL [Table3]. This relation is significant at $5 \%$ level of significance with $\mathrm{p}<$ 0.001 .

The cut-off for normal triglycerides was taken as $<250 \mathrm{mg} / \mathrm{dL}$, borderline as 250-350 and High as $>350 \mathrm{mg} / \mathrm{dL}$. The cut-off for IMT was taken as $0.7 \mathrm{~mm}$. Of the 84 patients [80\%] with abnormal intimal-medial thickness, 60 patients [70\%] had an abnormal triglyceride level and 24 patients [30\%] had normal triglyceride levels. Of the 22 patients with normal IMT, 15 patients [68\%] had normal triglycerides and 7 patients [32\%] had abnormal triglycerides [Table3]. This relation is highly significant statistically with $\mathrm{p}<0.001$ at $5 \%$ level of significance.

In a cross-sectional study conducted by Enomoto $M$ et al [22], and A case-control study by Debalina Sengupta et al ${ }^{[17]}$ showed a significant association between IMT and proatherogenic lipoprotein measurements was seen and the results of multiple linear regression analysis showed that the LDL-C/HDL-C ratio was the strongest predictor for IMT progression. 
Table 1: Characteristic Feature of study Population

\begin{tabular}{|l|l|l|}
\hline Variables & n(106) & \% \\
\hline Gender & 69 & 65 \\
\hline Male & 37 & 35 \\
\hline Female & \multicolumn{2}{|l|}{} \\
\hline Age Group in yrs & 6 & 5.6 \\
\hline $20-40$ & 31 & 29.2 \\
\hline $40-60$ & 69 & 65.2 \\
\hline$>60$ & \multicolumn{2}{|l|}{} \\
\hline Occupation & 21 & 21 \\
\hline Professional & 30 & 28 \\
\hline Skilled worker & 55 & 51 \\
\hline Unskilled worker & \multicolumn{2}{|l|}{} \\
\hline H/o Ischemic Heart Disease & 22 & 20 \\
\hline Yes & 84 & 80 \\
\hline No & \multicolumn{2}{|l}{} \\
\hline H/o Smoking & 26 & 24 \\
\hline Yes & 80 & 76 \\
\hline No &
\end{tabular}

Table 2: Relation between measured and expected IMT

\begin{tabular}{|l|l|l|}
\hline IMT & Measured & Expected \\
\hline Mean & 0.83 & 0.67 \\
\hline Std Deviation & 0.14 & 0.13 \\
\hline
\end{tabular}

The difference between the expected IMT and the measured IMT was significant at $5 \%$ level of significance with $\mathrm{p}<0.005$.

Table 3: Relation between Lipid profile and IMT

\begin{tabular}{|c|c|c|c|c|c|}
\hline \multirow{2}{*}{ Lipid Profile } & \multicolumn{2}{|c|}{ IMT } & \multirow[t]{2}{*}{ Total } & \multirow[t]{2}{*}{$\%$} & \multirow[t]{2}{*}{$P$ value } \\
\hline & $<0.7$ & $>=0.7$ & & & \\
\hline \multicolumn{6}{|l|}{ T. Cholesterol } \\
\hline Normal & 14 & 36 & 50 & 47 & \multirow{2}{*}{$>0.05$} \\
\hline Abnormal & 8 & 48 & 56 & 53 & \\
\hline \multicolumn{6}{|l|}{ LDL } \\
\hline Normal & 14 & 36 & 50 & 47 & \multirow{3}{*}{$<0.001$} \\
\hline Borderline & 5 & 12 & 17 & 16 & \\
\hline High & 3 & 36 & 39 & 37 & \\
\hline \multicolumn{5}{|l|}{ TG } & \\
\hline Normal & 15 & 24 & 39 & 37 & \multirow{3}{*}{$<0.001$} \\
\hline Borderline & 5 & 20 & 25 & 24 & \\
\hline High & 2 & 40 & 42 & 39 & \\
\hline \multicolumn{5}{|l|}{ HDL } & \multirow{4}{*}{$<0.001$} \\
\hline Low & 13 & 39 & 52 & 49 & \\
\hline Borderline & 7 & 37 & 44 & 42 & \\
\hline High & 8 & 2 & 10 & 9 & \\
\hline Total & 22 & 84 & 106 & 100 & \\
\hline
\end{tabular}


Fig1: Relation of Age with IMT

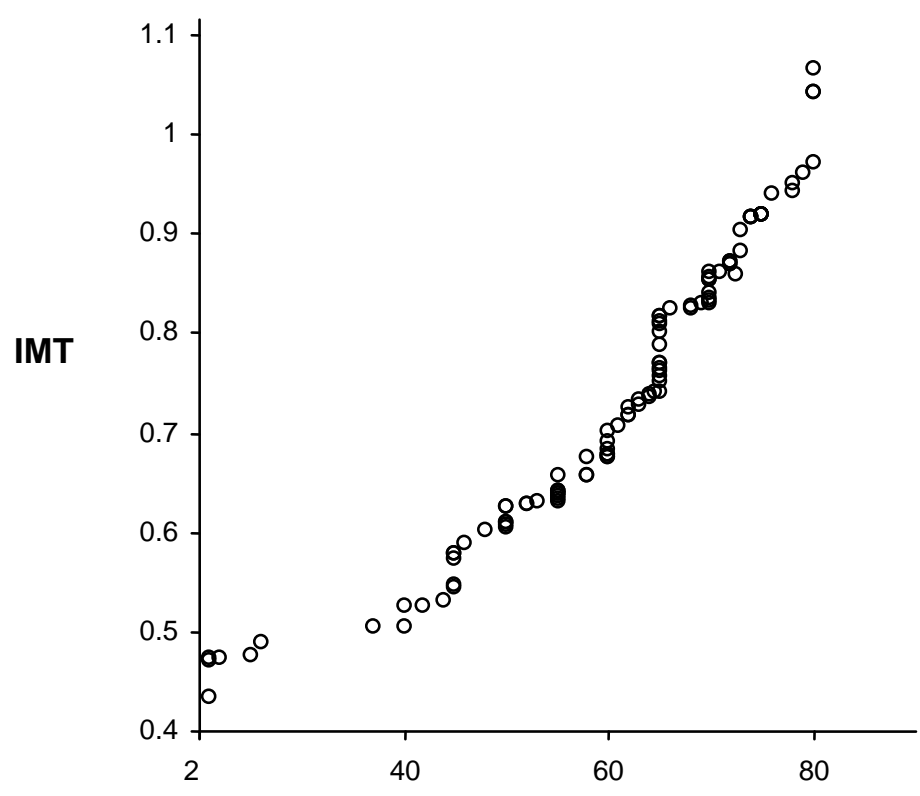

Age of patients

As is clear from the curve there is a linear relation between Age and IMT which is significant with $p<0.001$

Fig 2: Relation of hypertension with IMT

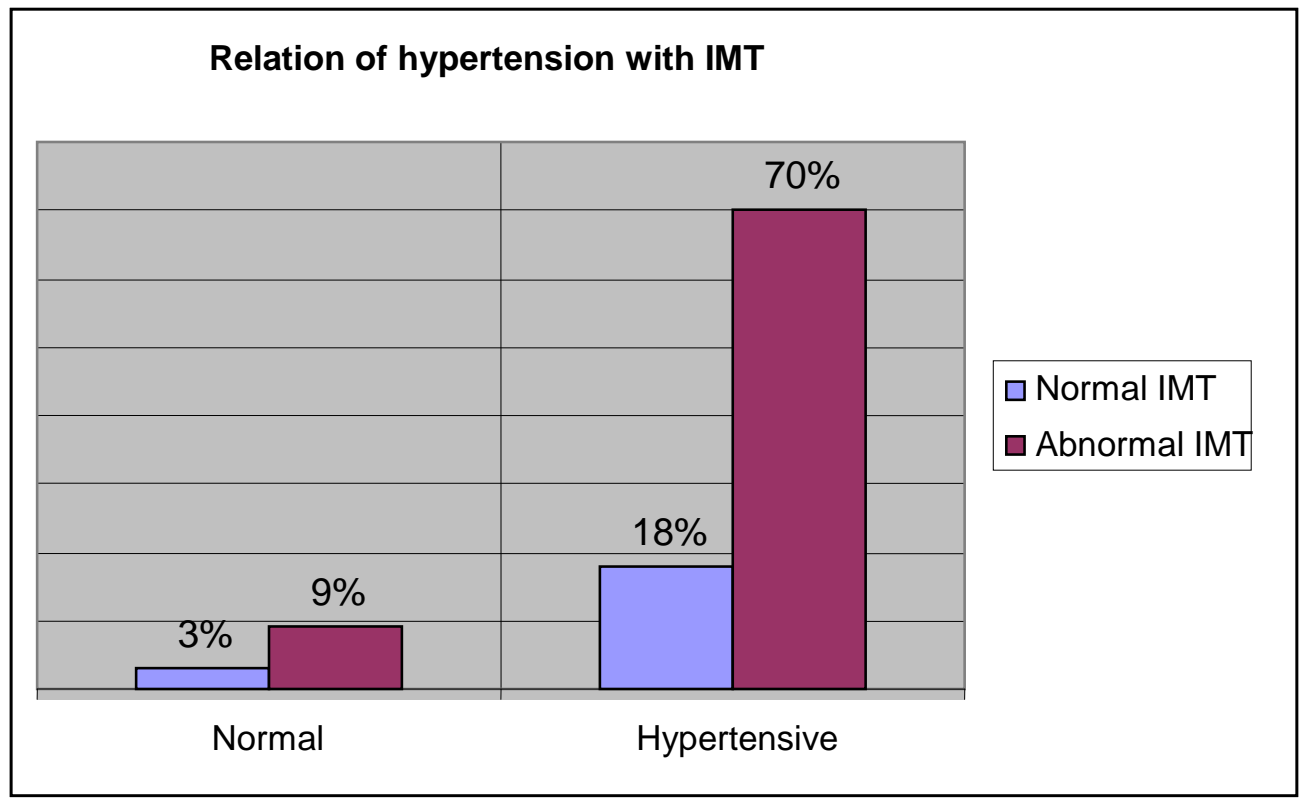

\section{Conclusion}

In patients with $\mathrm{CT}$ proven ischemic stroke, there is an increase in intimal-medial thickness of common carotid-internal carotid artery associated with increased age, hypertension and dyslipidaemia.
A statistically significant correlation was found between increased intimal-medial thickness in patients of ischemic stroke and abnormal serum LDL, abnormal serum triglycerides and serum HDL. 
The correlation of increased total cholesterol with intimal-medial thickness was not statistically significant

\section{Abbreviations \\ CT: Computed Tomography \\ HDL: High Density Lipoprotein \\ IMT: Intimal Medial Tickness \\ LDL: Low Density Lipoprotein \\ TG: Triglycerides}

\section{References}

1. Uma N, Chugh SK, Harshwardhan, Geol A, Gopal D.Echocardiography in patients with cerebral infarction. JAPI 1999; 47: 291-293.

2. Shahar E, Chambless L, Rosamond W, Boland L, Ballantyne C, McGovern P, Sharrett A. Plasma Lipid Profile and Incident Ischemic Stroke The Atherosclerosis Risk in Communities (ARIC) Study. Stroke 2003; 34:623.

3. Bots ML, Hoes AW, Koudstaal PJ, Hofman A, Grobbee DE. Common Carotid Intima-Media Thickness and Risk of Stroke and Myocardial Infarction: The Rotterdam Study. Circulation 1997;96(5):1432-7.

4. Salonen J, Salonen R. Ultrasonographically assessed carotid morphology and the risk of coronary heart disease. Arterioscler Thromb Vasc Biol 1991;11:1245-9.

5. Hofman A, Grobbee D, de Jong P, van den Ouweland FA. Determinants of disease and disability in the elderly: The Rotterdam Elderly Study. Eur J Epidemiol 1991;7:403-22.

6. Chambless LE, Heiss G, Folsom AR, et al.Association of coronary heart disease incidence with carotid arterial wall thickness and major risk factors: the Atherosclerosis Risk in Communities (ARIC) Study 1987-1993. Am J Epidemiol 1997;146:483-94.
7. Hodis HN, Mack W, LaBree L, Selzer RH, Liu CR, Liu CH, et al. The role of carotid arterial intima-media thickness in predicting clinical coronary events. Ann Intern Med 1998;128:262-9.

8. O'Leary DH, Polak JF, Kronmal RA, et al. Carotid-Artery Intima and Media Thickness as a Risk Factor for Myocardial Infarction and Stroke in Older Adults. N Engl J Med 1999;340(1):14-22

9. Homma Et al carotid plaque and intimamedia thickness assessed by B- Mode ultrasonography in subjects ranging from young adults to centenarians Stroke.ahajournals 2001;32:830-835

10. Executive Summary of The Third Report of The National Cholesterol Education Program (NCEP) Expert Panel on Detection, Evaluation, and Treatment of High Blood Cholesterol in Adults (Adult Treatment Panel III). JAMA 2001;285(19):2486-97.

11. Chobanian A, Black $\mathrm{H}$ et al. The seventh report of the joint national committee on prevention, detection, evaluation, and treatment of high blood pressure. The JNC 7 report. JAMA 2003;289(19):2560-72.

12. Clinical practice recommendations: American Diabetes Association; 2002.

13. Bhattacharya S, Prasarsaha S, Basu A, Das K. A 5 year prospective study of incidence, morbidity and mortality stroke profile on stroke in a rural community of Eastern India. J Indian Med Assoc 2005; 103 (12): 65510.

14. Dalal $\mathrm{P}$ et al. Population-bases stroke survey in Mumbai, India: Incidence and 28-day case fatality. Neuroepidemiology 2008; 31: 254-261.

15. Sridharan $S$ et al. Incidence, types, risk factors and outcome of stroke in a developing country: the Trivadrum Stroke Registry. Stroke 2009; 40: 1212-1218.

16. Meisinger C, Mraz W, Koenig W. Prognostic value of apolipoprotein B and 
A-I in the prediction of myocardial infarction in middle-aged men and women: results from the MONICA/KORA Augsburg cohort study. Eur Heart J 2005;26(3):271-8.

17. Sengupta D, Bardhan J, Mahapatra A, Banerjee $\mathrm{J}$ and Rout J Correlation between lipid profile \& carotid intima media thickness in cerebral ischemia Indian $\mathrm{J}$ Physiol Pharmacol 2014; 58(4) 354-364

18. Sun, Y et al. Carotid atherosclerosis, intima media thickness and risk factors--an analysis of 1781 asymptomatic subjects in Taiwan. Atherosclerosis 2002;164(1): 8994.

19. Geroulakos, $\mathrm{G}$ et al. The carotid intimamedia thickness as a marker of the presence of severe symptomatic coronary artery disease. Eur Heart J 1994;15(6):7815.

20. Lemne C, Jogestrand, de Faire T. Carotid intima-media thickness and plaque in borderline hypertension Stroke 1995 26(1):34-9.

21. Lacroix, $P$ et al. Carotid intima-media thickness as predictor of secondary events after coronary angioplasty. Int Angiol 2003; 22(3): 279-83

22. Enomoto M, Adachi H, Hirai Y, LDLC/HDL-C Ratio Predicts Carotid Intima Media Thickness Progression Better Than HDL-C or LDL-C Alone. Journal of Lipids 2011; ID 549137:6 